\title{
Hyperlipidemia in infant case of acute monoblastic leukemia
}

\author{
İbrahim Ece ${ }^{1, *}$, Murat Dogan ${ }^{1}$, Sinan Akbayram ${ }^{2}$, Nesrin Ceylan ${ }^{1}$, Nihat Demir $^{1}$, Kaan Demirören $^{1}$ \\ ${ }^{1}$ Department of Pediatric, Yuzuncu Yil University, Van, Turkey \\ ${ }^{2}$ Department of Pediatric Hematology, Yuzuncu Yil University, Van, Turkey
}

\begin{abstract}
Severe hyperlipidemia is a rare presentation usually associated with acute myeloid leukemia. 2-month-old girl complaining of discomfort. Her skin and conjunctivae were pale, abdominal distention and $5 \mathrm{~cm}$ hepatosplenomegaly were determined. Blood count revealed anemia $(10 \mathrm{~g} / \mathrm{dL})$ and thrombocytopenia $\left(41 \times 10^{9} / \mathrm{L}\right)$. Total leukocyte count was $24 \times 10^{9} / \mathrm{L}$, and on blood smear, $58 \%$ blast and $42 \%$ lymphocytes were seen. Bone marrow aspirate revealed diffuse infiltration with blast cells consistent with acute monoblastic leukemia. Her plasma had a milky appearance. In the laboratory examination, triglyceride level was $1428 \mathrm{mg} / \mathrm{dl}$, cholesterol level was $1291 \mathrm{mg} / \mathrm{dl}$. This case report illustrate that the hematological malignancies may present with severe hypertriglyceridemia.
\end{abstract}

Key Words: Child, leukemia, hyperlipidemia

\section{Introduction}

Leukemia is one of the most common pediatric cancers accounting for about $30 \%$ of diagnosis (1). There are two main subtypes; acute lymphoblastic leukemia (ALL) and acute myeloid leukemia (AML) AML is less common, accounting for approximately $18 \%$ of childhood leukemia diagnosis (1). About $20 \%$ of the cases of childhood AML are in children younger than 24 months; half of these cases occur within the first 12 months. Common presenting symptoms include fever, fatigue, pallor, bruising, petechiae, bone pain, infections not responding to appropriate antibiotic therapy (2).

Severe hypertriglyceridemia is rare and generally associated with either eruptive xanthomata or pancreatitis usually due to a primary deficiency in lipoprotein lipase (LPL) or its cofactor, apolipoprotein C-II, activity allied to other exacerbating factors, e.g. acute infection, obesity or diabetes. The association of severe hypertriglyceridemia (type IV or $\mathrm{V}$ hyperlipidaemia) with hematological or solid organ malignancy has only been noted to occur in rare acute cases (3).

In this report, we present hyperlipidemia in a case of AML because of rarely presentation. According to our knowledge, this is the first pediatric case with report AML associated with hyperlipidemia.

\section{Case report}

She was a 2-month-old girl complaining of discomfort. On physical examination, her skin and conjunctivae were pale, abdominal distention and $5 \mathrm{~cm}$ hepatosplenomegaly were determined. The main physical examination findings were unremarkable. Blood count revealed anemia (10 $\mathrm{g} / \mathrm{dL})$ and thrombocytopenia $\left(41 \times 10^{9} / \mathrm{L}\right)$. Total leukocyte count was $24 \times 10^{9} / \mathrm{L}$, and on blood smear, $58 \%$ blast and $42 \%$ lymphocytes were seen. Bone marrow aspirate revealed diffuse infiltration with blast cells consistent with acute monoblastic leukemia. Her plasma had a milky appearance. On the laboratory examination, triglyceride level was $1428 \mathrm{mg} / \mathrm{dl}$ (32-99 mg/dl), total cholesterol level was $1291 \mathrm{mg} / \mathrm{dl}$ (109-189 $\mathrm{mg} / \mathrm{dl})$, LDL cholesterol level was $870 \mathrm{mg} / \mathrm{dl}(60-150 \mathrm{mg} / \mathrm{dl})$, HDL cholesterol level was $12 \mathrm{mg} / \mathrm{dl}$ (35-84 $\mathrm{mg} / \mathrm{dl}$ ), very low density lipoprotein (VLDL) cholesterol level was $286 \mathrm{mg} / \mathrm{dl}(0-40 \mathrm{mg} / \mathrm{dl})$ and serum glucose level was $92 \mathrm{mg} / \mathrm{dL} \quad(70-110$ $\mathrm{mg} / \mathrm{dL}$ ). Serum amylase, pancreatic lipase, phosphor, sodium, potassium and calcium levels were normal range. Family history was negative for lipid disorders.

\section{Discussion}

The exact mechanism underlying the lipid abnormalities is not completely understood and 
remains to be elucidated. It has been suggested that it might be linked to an increase in endogenous hepatic synthesis of VLDL. Another suggested mechanism is decreased enzymatic activity of LPL, a key enzyme in the removal of triglyceride-rich lipoproteins from the plasma, resulting in decreased clearance and hypertriglyceridemia (4).

Severe hypertriglyceridemia $(>1000 \mathrm{mg} / \mathrm{dL})$ is a well-known side effect of induction chemotherapy in acute leukemia. This is usually secondary to combination with L-asparaginase and glucocorticoids, both of which are essential drugs in this treatment phase. Usually, hypertriglyceridemia is benign, transient and asymptomatic (5). Parsons et al. (5) reported 67\% of incidence of hypertriglyceridemia and $19 \%$ with levels greater than $1000 \mathrm{mg} / \mathrm{dl}$. Nesheli et al. was found of the 77 patients, $37(48 \%)$ received asparaginase therapy and $40(52 \%)$ patients did not. The mean peak triglyceride and cholesterol levels during asparaginase therapy in the first group were significantly higher than the levels in the second group (6). Tajima et al. demonstrated the synthesis of LPL has been in human monocytic leukemia cells indicating that this enzyme may play a role in tumour biology (7). Our patient had been diagnosed with AML and did not receive any chemotherapy.

This case report illustrate that the hematological malignancies may present with severe hypertriglyceridemia.

\section{References}

1. Puumala SE, Ross JA, Aplenc R, Spector LG. Epidemiology of childhood acute myeloid leukemia. Pediatr Blood Cancer 2013; 60: 728733.

2. Ching-Hon Pui. Childhood Leukemias. Jeffry ER, Bassem IR, Raul CR. Acute myeloid Leucemia. pp:499-539. Published by Cambridge University Press. Second Edition 2006.

3. Edwards CM, Stacpole PW. Rare secondary dyslipidaemias. In: Betteridge DJ, Illingworth DR, Shepherd J, eds. Lipoproteins in Health and Disease. London: Arnold, 1999: 1069-1098.

4. Cohen H, Bielorai B, Harats D, Toren A, PinhasHamiel O. Conservative treatment of Lasparaginase-associated lipid abnormalities in children with acute lymphoblastic leukemia. Pediatr Blood Cancer 2010; 54: 703-706.

5. Parsons SK, Skapek SX, Neufeld EJ, et al. Asparaginase associated lipid abnormalities in children with acute lymphoblastic leukemia. Blood 1997; 89: 1886-1895.

6. Nesheli HM, Tamaddoni A, Nesheli MM, et al. Lasparaginase induced hyperlipidaemia in acute lymphoblastic leukaemia. J Pak Med Assoc. 2013; 63: 324-326.

7. Tajima S, Hayashi R, Tsuchiya S, Miyake Y, Yamamoto A. Cells of a human monocytic leukaemia cell line (THP-1) synthesize and secrete apolipoprotein $\mathrm{E}$ and lipoprotein lipase. Biochem Biophys Res Commun 1985; 126: 526-531. 